\title{
Design and Fabrication of a Low Cost Field Vane Shear Apparatus
}

\author{
Mohammad Shahidur Rahman ${ }^{1}$ and Ahad Ullah ${ }^{2 *}$ \\ ${ }^{1}$ Department of Civil and Environmental Engineering, \\ Shahjalal University of Science and Technology (SUST), Sylhet, Bangladesh. \\ $2^{2 *}$ Department of Civil Engineering, Port City International University (PCIU), Chittagong, Bangladesh.
}

Received 18 March 2018; accepted 20 July 2018; available online 14 September 2018

DOI: https://10.30880/jst.2018.10.03.001

\begin{abstract}
The un-drained shear strength of soil is of great concern in many geotechnical engineering applications. The vane shear test is a simple, easy and popular type of in-situ shear test to the geotechnical engineers and geologists. However, it is not fairly appreciated by the academic personnel or field engineers as compared to the other shear strength test of soil. There are different types of field vane shear test apparatus existing in the market, but most of them are costly and have limited measuring capacity. The main objective of the research work was to develop a low cost field vane shear apparatus with higher measurement capacity using local materials and accessories. In this research work, a simple manually operated field vane shear apparatus was designed and fabricated. Four vane blades were welded to the vane shaft and a socket was added at the top. The most important component of the design apparatus is the torque wrench which is used to determine the torque both in clock and anti-clock wise direction. The torque value is then converted into the shear strength. The designed apparatus is suitable to determine the un-drained shear strength of soft to stiff clay soil up to $300 \mathrm{kPa}$. The performance of the device was tested directly in the crop field near Kumargaon area at Sylhet city. Average shear strength from in-situ test was found $49 \mathrm{kPa}$ for medium to stiff clay. For the assessment of accuracy of the designed apparatus, undisturbed soil sample was collected from the same location of the field and then tested by laboratory vane apparatus according to ASTM D4648 and fairly similar result was observed. The instrument's output repeatability was checked from the test data and the values were found quite satisfactory with a range of 2.68 to 5.87. The designed apparatus are about five times cheaper than the conventional apparatus available in the market.
\end{abstract}

Keywords: Design; Field vane shear; Low cost; Shear strength; Soil.

\section{Introduction}

The importance of reliable soil parameters in any geotechnical analysis has been emphasized over and over again. Geotechnical properties such as shear strength of soil can be assessed by proper laboratory testing or in situ testing. The vane shear test is a very simple type of in-situ shear test for soft cohesive soil. However, it is not fairly appreciated by the academic personnel or field engineers as compared to the other shear strength test of soil. But it is an easy and quick in-situ method to find the un-drained shear strength of clay formation during reconnaissance survey or where soil samples for laboratory testing cannot be collected easily. The reliability of test results varies depending on the type and condition of the soil. For shear strength determination of clay soil, mainly two types of laboratory tests are widely performed such as, the unconfined compressive strength test and the tri-axial shear strength test.

However, there is no suitable field test for soft cohesive soil except vane shear test. Many of the structures in Bangladesh constructed on shallow depth supported by different shallow foundation options. Therefore, in this work, emphasis was given to develop a simple vane shear apparatus which can determine the undrained shear strength at shallow depth with minimum efforts. Many ground improvement techniques involve the preparation of compacted sand bed on soft soil layer. In that case, after improving the ground bed, it is necessary to determine the degree of improved strength. But unfortunately, our local people show no interest to reassess the strength improved by ground improvement technique. Rather they roughly estimate the bearing capacity value just using some thumb rules. For 
this reason, a simple portable tool is required by which the in-situ improved strength of soil at shallow depth can be determined easily and cheaply.

The field vane shear test was originally used in Sweden in 1919. It has been employed extensively on a worldwide basis since the late 1940s, following pioneering development work by, among others, Carlsson [1], Skempton [2], and Cadling and Odenstad [3]. A detailed history of the use of the field vane is given by Flodin and Broms [4]. Field vane shear test is primarily used to obtain the maximum undrained shear strength in soft to very soft saturated clays [5]. This test enables the direct measurement of the un-drained shear resistance of saturated cohesive soils. It can be carried out either in the field, on the wall or at the bottom of an excavation. The test consists of forcing into the soil a vane equipped with four orthogonal blades and then rotating until the soil failure. Maximum torque value must be measured and recorded [6].

There are different types of field vane shear tester available in the market now. A short list of such conventional vane shear apparatus is presented in Table 1. Moreover literature reveals that the $\mathrm{H}-10$ and $\mathrm{H}-70$ field vane shear apparatus is used for soft to medium stiff clays with a measurement capacity of $0-100 \mathrm{kPa}$ and $0-80 \mathrm{kPa}$ respectively [9]. In addition, H-60 field vane shear apparatus is used for soft to stiff clays with a measurement capacity of 0$200 \mathrm{kPa}$ [9]. Actually, hand vane tester provides quick and accurate shear strength values of cohesive soils. It has light weight carrying case for easy transport to the field [10].

Table 1 Conventional vane shear apparatus available in the market $[7,8]$

\begin{tabular}{|c|l|c|c|c|c|}
\hline $\begin{array}{c}\text { Sl. } \\
\text { No }\end{array}$ & \multicolumn{1}{|c|}{ Name } & Materials & Power & $\begin{array}{c}\text { Range } \\
(\mathrm{kPa})\end{array}$ & $\begin{array}{c}\text { Price } \\
(\mathrm{USD})\end{array}$ \\
\hline 1 & Field Vane Shear Test Apparatus & Steel & Manual & - & 580 \\
\hline 2 & Portable Vane Shear Test/PVST & Stainless steel & Manual & $0-260$ & $400-600$ \\
\hline 3 & Portable Vane Shear Test/PVST & Steel & Electric & - & 9000 \\
\hline 4 & C041 Four-bladed Situ Vane Shear Test & Steel & Electric & - & $1200-$ \\
1500
\end{tabular}

\section{Design specifications}

Main design criteria for the apparatus were taken from ASTM D2573-01 [11] (Standard
Test Method for Field Vane Shear Test in Cohesive Soil). Here Table 2 enlists some important technical specifications of the currently developed vane shear apparatus.

Table 2 Technical specifications of the developed field vane shear apparatus

\begin{tabular}{|l|l|l|}
\hline Particular & Standard (ASTM D2573-01) [5] & Present apparatus \\
\hline Vane Diameter (D) & 35 to $100 \mathrm{~mm}(1.5$ to 4 in.) & $63.5 \mathrm{~mm}(2.5 \mathrm{in})$. \\
\hline Vane Shaft Diameter (d) & 12.5 to $16.5 \mathrm{~mm}(0.5 \mathrm{in})$. & $12.7 \mathrm{~mm}(0.5 \mathrm{in})$. \\
\hline Vane Height (H) & $1 \mathrm{D} \leq \mathrm{H} \leq 2.5 \mathrm{D}$ & $2 \mathrm{D}(5 \mathrm{in})$. \\
\hline Blade Thickness (e) & e $<3 \mathrm{~mm}(0.006$ to $0.125 \mathrm{in})$. & $\mathrm{e}=1.5875 \mathrm{~mm}(1 / 16 \mathrm{in})$. \\
\hline Taper Angle (i) & $\begin{array}{l}\text { Usually 0 degree (rectangular) or } 45 \\
\text { degrees (tapered) }\end{array}$ & Rectangular \\
\hline Vane Area Ratio & Less than $12 \%$. & $8.89 \%$ \\
\hline
\end{tabular}




\section{Fabrication of the apparatus}

At first, four steel blades ( 1 inch $\times 5$ inch) were welded at the bottom of a 30 inch long steel vane shaft ( 0.5 inch diameter). Then a half inch socket was joined at the top of the vane shaft as illustrated in Fig. 1.

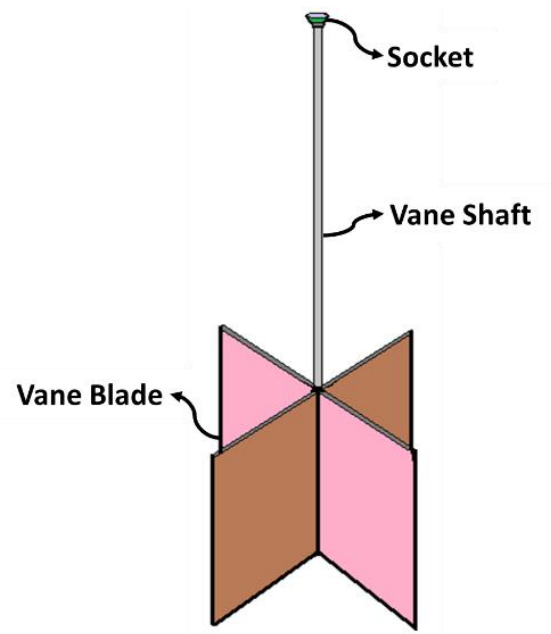

Fig. 1 Schematic diagram of the field vane apparatus (main part)

\subsection{Vane}

The vane consists of four blades and the thickness of each blade was $1.5875 \mathrm{~mm}(0.0625$ in.). Vanes were fabricated of high quality steel sheet. The edge of the vanes were made smooth and flat. The vane diameter was large enough to provide optimum torque resolution. For softer soils, larger sizes are required for good resolution and small sizes are required for hard soil to avoid possible damage to the torque measuring device.

\subsection{Vane shaft}

The vane was connected with a steel vane shaft of diameter 0.5 inch and a socket was also fixed on the top of the shaft to hold the torque wrench in position. This vane shaft was fabricated with hard steel of sufficient thickness to carry the imposed stress delivered from the wrench without any twisting effect.

\subsection{Torque measuring device}

For measuring the soil shear strength, torque was applied to the vane shaft and thereby the vane also. This is accomplished with a clamping device ( 0.5 inch socket). The torque application apparatus was placed at the top of the shaft to apply the torque directly by a hand operated torque wrench with a dial gauge of capacity $0-300 \mathrm{kPa}$.

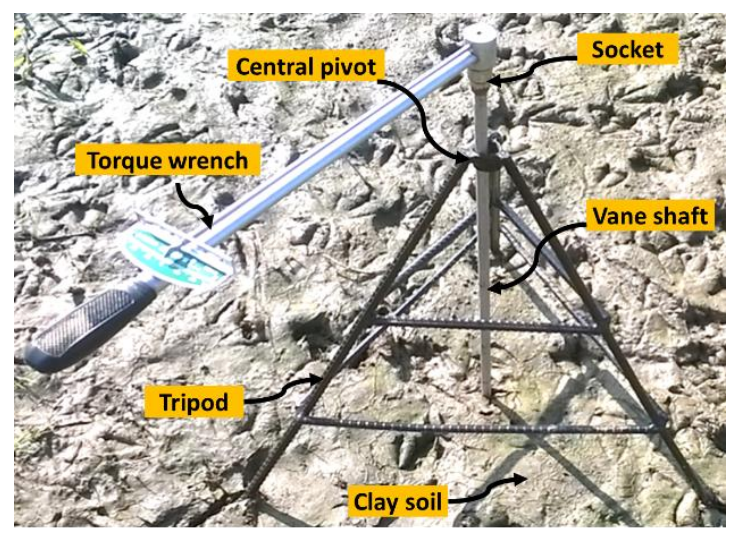

Fig. 2 Complete assembly of the fabricated field vane apparatus placed in a crop field

\subsection{Tripod with central pivot}

A special type of tripod with a central pivot was used to allow the vane pushing vertically into the soft ground before commencement of the test and prevent buckling of the device during torque application. It was designed to support the shaft as well as to minimize the rod friction during operation of the apparatus.

\section{Methods for Testing and Calculation}

a) At first, the test location was selected and the tripod was fixed with the vane at the test location.

b) The vane was driven gently into the ground to the required position. It was pushed down without any application of shocks, blows, vibration, or rotation. No torque was applied to the shafts during the pushing.

c) The torque wrench was placed into the socket at the top of the vane shaft.

d) The graduated scale of the torque wrench was set to zero position. The time elapse between vane penetration and torque wrench operation was not more than 5 minutes. To minimize frictional loss between the vane shaft and central pivot of the tripod, the inner surface of the ring was well lubricated.

e) The handle of the torque wrench was rotated in the clockwise or anti-clockwise direction. Turning was done very slowly with constant speed at a rate of 0.1 degree/sec keeping the vane at a fixed 
position.

f) Maximum applied torque was recorded at the field. The torque is then converted into shear strength.

The un-drained shear strength is calculated using the following equation (for a rectangular vane of $\mathrm{H} / \mathrm{D}=2$ ).

$$
S_{u}=\frac{6 T_{\max }}{7 \pi D^{3}}
$$

Where, $S_{\mathrm{u}}=$ Un-drained shear strength, $\mathrm{T}_{\max }=$ Maximum torque applied, $\mathrm{D}=$ Vane diameter and $\mathrm{H}=$ Height of vane.

\section{Results and discussions}

For checking the accuracy of the fabricated vane shear apparatus, five test sites were selected on the basis of availability of soft clay deposition in shallow depth in nearby area. The field vane shear test was performed in all these five test locations (denoted as A, B, C, D and E). In addition to that, five un-disturbed soil samples were collected from the same location to carry out the laboratory vane shear test with unchanged moisture content.

The field and collected soil samples were visually classified and it was found that the soil samples resembled to lean clay (CL) to fat clay or high plasticity clay $(\mathrm{CH})$ which contain about $50-64 \%$ clay, $20-37 \%$ silt and $5-16 \%$ sand. The liquid limit of A, B, C, D and E soil samples were $32-50 \%, 33-57 \%, 30-49 \%$, 32$55 \%$ and $32-51 \%$ and plastic limit were $21-$ $29 \%, 23-30 \%, 20-28 \%, 21-29 \%$ and $22-29 \%$ respectively.

Shear strength obtained from the fifteen insitu field vane shear test from five test sites at six inch depth is summarized in the Table 3 . It shows that the values of shear strength at the same site are closer, but slightly vary for different moisture content. The shear strength values of the soil samples for almost similar water content varied due to variability in soil formation, sample preparation and handling, degree of consolidation etc. The result found in the laboratory test using vane shear apparatus was almost similar to the field test.

Table 3 Field vane shear test data

\begin{tabular}{|c|c|c|c|c|c|c|c|c|c|}
\hline No. & $\begin{array}{c}\text { Torque, } \\
\text { N-m }\end{array}$ & $\begin{array}{c}\text { Shear } \\
\text { Strength, } \\
\mathrm{c}_{\mathrm{u}}(\mathrm{kPa})\end{array}$ & $\begin{array}{c}\text { Standard } \\
\text { deviation, } \\
\boldsymbol{\sigma}\end{array}$ & $\begin{array}{c}\text { Water } \\
\text { Content, } \\
\text { w\% }\end{array}$ & No. & $\begin{array}{c}\text { Torque, } \\
\text { N-m }\end{array}$ & $\begin{array}{c}\text { Shear } \\
\text { Strength, } \\
\mathrm{c}_{\mathrm{u}}(\mathrm{kPa})\end{array}$ & $\begin{array}{c}\text { Standard } \\
\text { deviation, } \\
\boldsymbol{\sigma}\end{array}$ & $\begin{array}{c}\text { Water } \\
\text { Content, } \\
\text { w\% }\end{array}$ \\
\hline A1 & 51 & 54.34407 & \multirow{3}{*}{2.68} & 32.8 & D1 & 40 & 42.6228 & \multirow{3}{*}{5.87} & 39.46 \\
\hline $\mathrm{A} 2$ & 54 & 57.54078 & & 31.8 & D2 & 45 & 47.9506 & & 36.64 \\
\hline A3 & 56 & 59.67192 & & 29.6 & D3 & 51 & 54.3440 & & 32.55 \\
\hline B1 & 55 & 58.60635 & \multirow{3}{*}{3.84} & 34.66 & E1 & 35 & 37.2949 & \multirow{3}{*}{1.63} & 35.13 \\
\hline B2 & 60 & 63.93420 & & 33.82 & E2 & 37 & 39.42609 & & 34.66 \\
\hline B3 & 62 & 66.06534 & & 33.13 & E3 & 38 & 40.49166 & & 34.32 \\
\hline $\mathrm{C} 1$ & 30 & 31.96710 & \multirow{3}{*}{5.64} & 36.04 & & & & & \\
\hline $\mathrm{C} 2$ & 38 & 40.49166 & & 33.33 & & & & & \\
\hline $\mathrm{C} 3$ & 40 & 42.6228 & & 30.50 & & & & & \\
\hline
\end{tabular}

All the values of shear strength found in the field test were in the range of medium to stiff clay according to ISO 14688-2:2004 [12]. A previous study also reported that the value of un-drained shear strength is $20-48 \mathrm{kPa}$ at the depth of $10 \mathrm{~cm}$ for field vane shear test at different types of soft clay [13]. Although the test soils under this study were not as like as the soil reported in the literature, the test result obtained by the present fabricated apparatus had shown quite similar trend of strength (32$66 \mathrm{kPa}$ ). The instrument's output repeatability was checked from the test data obtained from fifteen soil samples in five different locations. The repeatability values were found quite satisfactory with a range of 1.63-5.87.

The conventional apparatus are quite costly ranging from 400 to 9000 USD and the maximum measuring capacity is $260 \mathrm{kPa}[7,8]$. Whereas, the design apparatus cost only about 120 USD and the maximum measurement capacity is $300 \mathrm{kPa}$. Moreover, the present apparatus can apply torque in both clock-wise and anti-clock-wise direction. This special feature enables the product to be used in determination of the strength sensitivity of clay soil in reverse application of torque. 


\section{Conclusion}

A simple cost effective field vane shear test apparatus was designed and fabricated with locally available accessories and materials. This field vane shear test apparatus can be easily used to determine the undrained shear strength of clay soil at shallow depth. Field vane shear test was conducted near Kumargaon at Sylhet city area and the result was found as $49 \mathrm{kPa}$ on average from the field test which indicates the firm to stiff consistency of clay deposition. This type of product could easily be fabricated in the laboratory in a cost effective way following standard method. The academic researchers and the private consultants (construction field) could easily use this type of item for the field strength test of soft, saturated, cohesive clayey soils. However, it will be appreciable if the field value observed by this tool could be compared with some commercial apparatus available in the market conforming the same field condition.

\section{References}

[1] Carlson, L. (1948) Determination in Situ of the Shear Strength of Undisturbed Clay by Means of a Rotating Auger, Proceedings of the 2nd International Conference on Soil Mechanics and Foundation Engineering, Vol. 1, pp. 265-270.

[2] Skempton, A. W. (1948) Vane Tests in the Alluvial Plain of the River Forth Near Grangemouth, Geotechnique, Vol. 1, pp. 111-124.

[3] Cadling, L. and Odenstad, S. (1948) The Vane Borer, Royal Swedish Geotechnical Institute, Proceedings No. 2.

[4] Flodin, N. and Broms, B. (1981) Soft Clay
Engineering, E. W. Brand and R. P. Brenner, Eds., Elsevier, Amsterdam, The Netherlands, pp. 27-308.

[5] Civil engineers forum.com, retrieved on 28 Nov 2015 from http://civilengineersforum.com/field-vanetest.

[6] Pagani-geotechnical.com, retrieved on 28 Nov 2015 from

http://www.paganigeotechnical.com/index. php/en/ct-menu-item-13/ct-menu-item-43.

[7] Alibaba.com, retrieved on 4 July 2018 from https://www.alibaba.com/photo/vaneshear-testphotos.html

[8] Indiamart.com, retrieved on 5 July 2018 from

https://www.indiamart.com

[9] H-10, H-60, H-70 Field Vane Shear Apparatus, Hoskin Scientific Ltd. retrieved on 28 Nov 2015 from http://www.hoskin.ca/catalog/

[10] Hand Vane Tester, Hoskin Scientific Ltd. retrieved on 28 Nov 2015 from http://www.hoskin.ca/catalog/index.php

[11] ASTM D2573-01, (2004) Standard Test Method for Field Vane Shear Test in Cohesive Soil, Annual Book of ASTM Standards, D 4648-00, 04.08, American Society for Testing and Materials.

[12] ISO 14688-2, (2004) Geotechnical Investigation and Testing - Identification and Classification of Soil - Part 2: Principles for a classification 2 .

[13] Jung, H.S, Cho, C.G. and Chun, B.S. (2010) The Engineering Properties of Surface Layer on Very Soft Clay of the South Coast in Korea, 2nd International Symposium on Cone Penetration Testing, CPT'10. 